\title{
A New Method for Assessing the Sex of Fragmentary Skeletal Remains: Femoral Shaft Circumference
}

\author{
THOMAS K. BLACK III \\ Museum of Anthropology, The University of Michigan, Ann Arbor, Michigan 48109
}

\begin{abstract}
KEY WORDS Sexual identification . Discriminant function . Fragmentary remains
\end{abstract}

\begin{abstract}
A simple discriminant function using midshaft femoral circumference for the determination of sex has been tested with 114 skeletons from the Libben Site, Ontario County, Ohio. The results have been shown to be $85 \%$ consistent with other, accepted means of determining sex. Femur circumference can be an aid to the sexual identification of poorly preserved and fragmentary skeletal remains.
\end{abstract}

Most of the techniques presently available for the sexual assessment of human skeletal remains can be used only on well-preserved bones from relatively complete skeletons. Few reliable means of sexing are available to the osteologist confronted with poorly preserved bones or fragmentary or mixed skeletons. By way of example, one of the most accurate means of sexing the pelvis is dependent on the preservation of the os pubis (Phenice, '69). Unfortunately, this part of the pelvis is often poorly preserved, and is completely missing from some skeletal collections. The sex of the skull may be assessed by visual inspection or by making measurements and employing discriminant functions. Yet, fragmentary crania can not always be reconstructed to permit measurements, and diagnostic features such as the mastoid process can be broken off and lost. Even well-preserved bones can cause problems of sexing when they are intermingled in multiple interments, such as ossuaries. So, there is a definite need for techniques of sexual determination that will work with poorly preserved remains and with individual bones.

Techniques which require the measurement of the diameters, circumferences, or cross-sectional areas of the tubular bones may provide the needed means for sexing fragmentary remains. Several advantages of widths over lengths are apparent. The sexual dimorphism in widths, circumferences, and areas often exceeds the sexual dimorphism in bone lengths. For example, among adult American whites, the length of the second metacarpal of the males exceeds the length of the second metacarpal of the females by an average of about $9 \%$, but the midshaft width and circumference are about $16 \%$ greater, and the cross-sectional area is roughly $30 \%$ greater (Frisancho et al., '70; and data from Garn, '70; Garn et al., '76). The dimorphism in bone diameters is due to sexual differences in bone remodeling in the tubular bones during adolescence. During adolescence, cortical bone is laid down at a greater rate in males than in females, and, in males, a larger proportion of the bony growth is at the subperiosteal surface, so male tubular bones increase their circumference more than those of females during adolescence (Frisancho et al., '70; Garn, '70). The cross-sectional area (and the diameter and circumference) of the tubular bones of both sexes continues to increase throughout life, but at a greatly reduced rate from that of adolescence, and male bones remain larger than female bones throughout adult life (Garn, '72). The other advantage of circumferences over lengths derives from differences in preservation and restorability. In general, it is easier to restore the comparatively thick cortical bone for a circumferential measurement than it is to restore fragile cancellous bone for a measurement of length.

Several considerations must be made in choosing the tubular bones to consider in the diagnosis of sex. Although much research has been done with the metacarpals, these small bones are often too poorly preserved to be of 
any use. And, because of their small size, a measurement error as small as half a millimeter can amount to $5 \%$ or $6 \%$ of the total measurement. For these reasons, larger bones are to be preferred.

\section{MATERIALS AND METHODS}

The need for a technique of identifying sex based on bone circumference arose during the study of a poorly preserved skeletal series from a badly disturbed cemetery in Southeast Missouri. Although some of the adult skeletons could be sexed by either the sciatic notch of the pelvis or by cranial form, nearly two-thirds of the adults could not be sexed by these techniques. Because the best represented tubular bone in the skeletal series was the femur, and because the femora appeared to include a wide range of variability in circumference, the relationship of femoral circumference to sex was investigated. Femoral circumference at midshaft was measured to the nearest millimeter with a cloth tape. When circumference was measured, the cloth tape was made to follow the contours of the bone, even on femora with prominent lineae aspera.

Male femur circumference was significantly larger than female femur circumference. The midpoint between the male and female means was used as a dividing point for assigning sex to the femora of 46 previously unsexed individuals.

Because a small sample had been used to compute the discriminant function, and because the initial sexing of the skeletons was probably only $80-90 \%$ accurate, another test was necessary.

The femoral circumference of 63 males and 51 females aged 20 years or greater from the Libben Site, Ontario County, Ohio, were measured by one observer (C. O. L.). All skeletons were sexed by the Phenice ('69) method. The ages of 60 of the males and 46 of the females were determined from weighted estimates based on six indicators of age (Lovejoy, personal communication).

The distribution of the femoral circumferences for each sex was tested and found to be normal. Student's $t$ was computed to test for any age dependency in the femoral circumferences and for equality of the mean ages of the two sexes.

A regression analysis was performed for each sex to test for any age dependency in the femoral circumference. This test was necessary because it has been shown that the subperiosteal diameter of tubular bones increases throughout life (Garn, '70; Smith and Walker, '64). Three discriminant functions were then computed using statistical procedures incorporated into the Michigan Interactive Data Analysis System (MIDAS). The first function had one independent variable, femur circumference. The second function had two independent variables, femur circumference and individual age. For purposes of comparison, a third discriminant function, based on maximum femoral length (Stewart, '52) alone, was computed.

\section{RESULTS}

Student's $t$-test confirmed that the mean male femoral circumference was significantly greater than the female mean, even though the mean male age was significantly less than the female mean (table 1). A regression analysis was performed to determine whether age contributed significantly to the male-female differences in femoral circumference.

The slope of the regression line was significantly different from zero for males, but not for females. However, the value of $\mathrm{R}^{2}$ for the male regression equation, 0.12 , was quite low, indicating that age explained only a small portion of the variability of femur circumference. Nevertheless, age was included as an independent variable for the second discriminant

TABLE 1

Descriptive statistics

\begin{tabular}{|c|c|c|c|c|c|c|c|c|c|}
\hline & \multicolumn{3}{|c|}{ Femoral circumference } & \multicolumn{3}{|c|}{ Age } & \multicolumn{3}{|c|}{ Femoral length } \\
\hline & $\mathbf{N}$ & Mean & S.D. & $\mathrm{N}$ & Mean & S.D. & $\mathbf{N}$ & Mean & S.D. \\
\hline & & $m m$ & $m m$ & & years & years & & $m m$ & $m m$ \\
\hline Males & 63 & 85.1 & 4.1 & 60 & 32.1 & 5.9 & 63 & 464.5 & 18.6 \\
\hline Females & 51 & 77.4 & 4.2 & 46 & 36.3 & 10.2 & 50 & 426.7 & 15.8 \\
\hline$t$ & & 9.75 & & & 2.65 & & & 11.47 & \\
\hline $\mathrm{p}$ & & $<0.001$ & & & $<0.01$ & & & $<0.001$ & \\
\hline
\end{tabular}


function because of the possibility that it would increase its discriminatory power.

The first discriminant function included only femur circumference as an independent variable (table 2 ). The midpoint between the male mean $(85.1 \mathrm{~mm})$ and the female mean $(77.4 \mathrm{~mm})$ was used as a sectioning point for the assignment of sex. The midpoint, $81.2 \mathrm{~mm}$ was rounded down to $81 \mathrm{~mm}$, since the measurements had been recorded only to the nearest millimeter. Individuals with a femur circumference greater than $81 \mathrm{~mm}$ were classified as males, those with a femur circum. ference less than $81 \mathrm{~mm}$ were classified as females, and those with a femur circumference equal to $81 \mathrm{~mm}$ were classified as indeterminate sex (fig 1). Of the 107 individuals who were assigned a sex by the first discriminant function, $85.0 \%$ were correctly assigned (50 of 57 males and 41 of 50 females).

A second discriminant function was computed, using femoral circumference and age as the independent variables (table 2). This function correctly assigned sex to $85.8 \%$ of the individuals of known age (54 of 60 males and 37 of 46 females). This represents little improvement over the function based solely on femoral circumference. However, it is important to note that no males were aged over 45 years and no females were aged over 55 years, and it is possible that age would become an important variable in populations with a larger proportion of elderly individuals.

A third discriminant function was computed to allow comparison of the discriminatory effectiveness of the femoral lengths with their circumferences. This one variable function was computed in the same manner as the first discriminant function. The average of the mean male femoral length $(464.5 \mathrm{~mm})$ and the mean female femoral length $(426.7 \mathrm{~mm})$ was used as a sectioning point for the assignment of sex. Individuals with a maximum femoral length less than or equal to $445 \mathrm{~mm}$ were assigned the female sex, while those with a length greater than or equal to $446 \mathrm{~mm}$ were assigned the male sex (table 2 ). Of 113 individuals assigned a sex by femoral length, $89.4 \%$ were correctly assigned ( 57 of 63 males and 44 of 50 females).

\section{DISCUSSION}

The results of these simple discriminant analyses compare favorably with the results of more complex means of sexing. Krogman ('62) and Stewart ('48) claimed only 80-90\% accuracy for sexing the skull by observation. Giles and Elliot ('63) reported a range of from $81 \%$ to $89 \%$ accuracy for discriminant functions using from four to eight cranial measurements. Giles ('64) achieved $82 \%$ to $85 \%$ accuracy in sexing the mandible using dis criminant functions based on from three to six measurements. Ditch and Rose (72) sexed prehistoric dentitions with from $88 \%$ to $95 \%$ accuracy using combinations of from three to five dental measurements.

It is clear, then, that $85-89 \%$ represents high accuracy for discriminant functions using only one measurement. It is interesting to note that although femoral circumference had a slightly higher percent sexual dimorphism (calculated as $100(\mathrm{M} / \mathrm{F}-1.0)$ ) than femoral length $(9.9 \%$ to $8.8 \%)$, the simple discrimination based on length was more effective than the one based on circumference. However, the thick cortical bone at the midshaft of the femur makes it very durable and resistant to

TABLE 2

Discriminant functions

\begin{tabular}{|c|c|c|c|}
\hline \multirow{2}{*}{ Functions ${ }^{1.2}$} & \multicolumn{3}{|c|}{$\begin{array}{c}\text { Percent } \\
\text { correctly classified }\end{array}$} \\
\hline & Male & Female & Total \\
\hline $\begin{array}{l}\text { 1. Function using femoral circumference alone: } \\
\text { (femoral circumference) }-81\end{array}$ & 87.7 & 82.0 & 85.0 \\
\hline $\begin{array}{l}\text { 2. Function using femoral circumference and } \\
\text { individual age: } \\
\text { (femoral circumference) }+0.0921 \text { (age) }-72.41\end{array}$ & 90.0 & 80.4 & 85.8 \\
\hline $\begin{array}{l}\text { 3. Function using femoral length alone: } \\
\text { (femoral length) }-445.6\end{array}$ & 90.5 & 88.0 & 89.4 \\
\hline
\end{tabular}

\footnotetext{
- Circumference and length are measured in millimeters, age is measured in years.

${ }^{2}$ Individuals with a score on a discriminant function greater than 0.0 are classified as males; those with a score less than 0.0 are classified as females; those with a score equal to 0.0 are unclassified.
} 


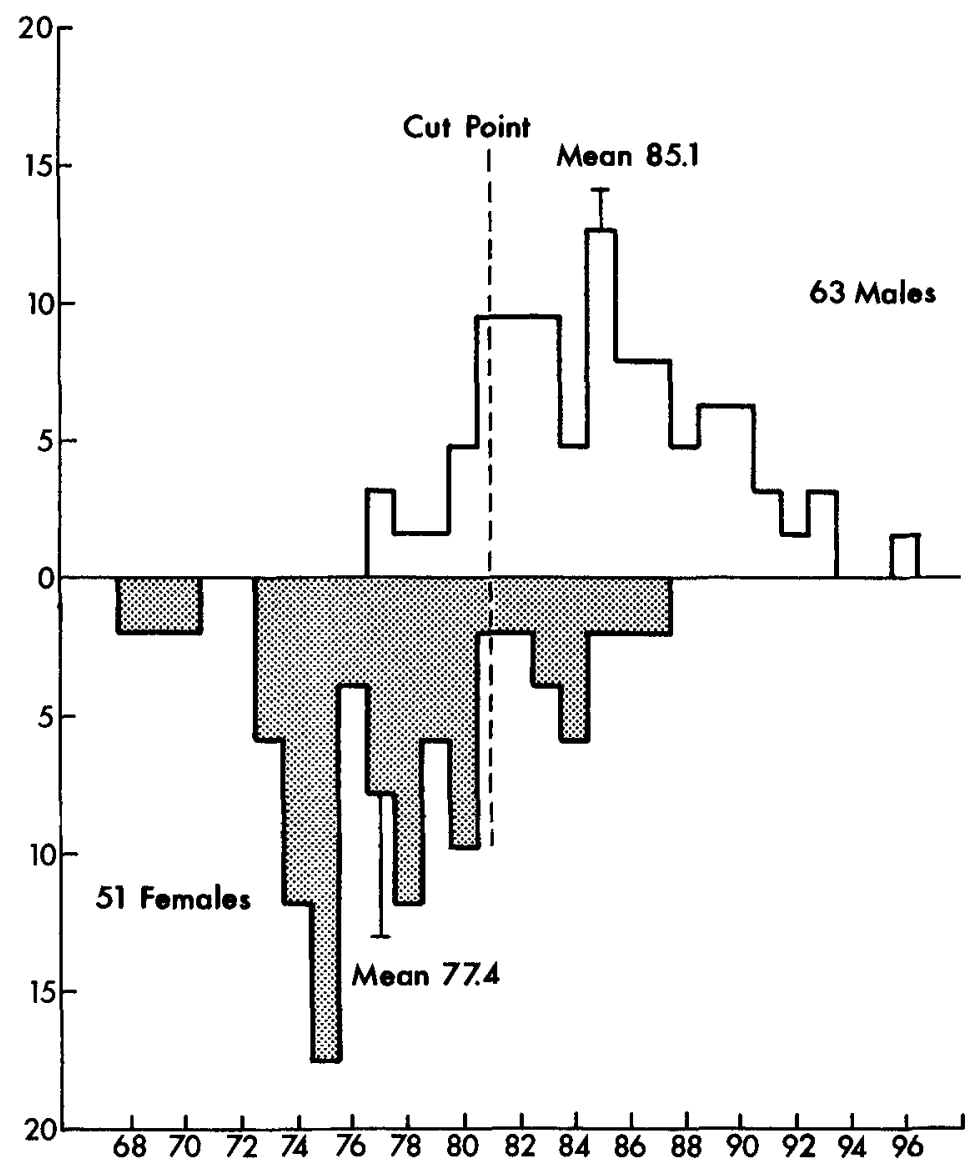

Fig. 1 The percentage distribution of the male and female femoral circumferences with respect to the cut point determined by the discriminant function based on femoral circumference alone. Individuals to the right of the cut point would be classified as males, individuals to the left would be classified as females, and those at the cut point would be unclassified.

accidental breakage, so that the circumferential measurement can be readily made on bones for which no length measurement can be made. Thus, the method based on femoral circumference should prove useful in identifying the sex of damaged or disturbed human skeletal remains.

There are a few limitations to the application of this technique. First, a new function should be calculated for each population to be considered. It is unlikely that two biologically distinct populations would be correctly sexed by the same function (see cautionary note in Garn et al., '72). Second, the method has been tested only with prehistoric populations. Although these populations may be reliably sexed, we can not be certain of the true sex of any individual. For this reason, it is not strict- ly correct to say that the sexing was $85 \%$ "accurate." Instead, the proper term should be "consistent." If the true sexes of these individuals were known, the accuracy figure might go as high as $90 \%$, or it could drop below $80 \%$. If the method were tested against a modern skeletal collection of known race and sex, slightly poorer results would be expected, since most of these populations are more biologically heterogeneous than the prehistoric populations considered here. Third, the influence of increasing age on sexual determinations based on femoral circumference is not yet clear. Just eight individuals over 45 years of age, all of them female, were included in the Libben sample. Again, a large modern skeletal population could be used to investigate the contribution of age to femoral circumference. 
Despite these limitations, it appears that femoral circumference can be a useful tool in the determination of sex, especially where the skeletal remains are fragmentary or poorly preserved. For skeletal collections in good condition, femoral circumference can serve as a rapid and reliable corroboration of sexual assessments made by other means. It should be emphasized that the functions presented here should not be applied indiscriminately to other skeletal populations. New functions should be computed for each population to be considered.

\section{ACKNOWLEDGMENTS}

C. Owen Lovejoy of Kent State University provided the bone measurements and the age and sex estimates for the Libben material. Stanley M. Garn of the Center for Human Growth and Development, Alan S. Ryan of the Museum of Anthropology, and Clark S. Larsen of the Department of Anthropology, all of the University of Michigan, provided useful criticism of earlier drafts of this paper.

\section{LITERATURE CITED}

Ditch, L. E., and J. C. Rose 1972 A multivariate dental sex ing technique. Am. J. Phys. Anthrop., 37: 61-64.

Frisancho, A. R., S. M. Garn and W. Ascoli 1970 Subperiosteal and endosteal bone apposition during adolescence. Hum. Biol., 42: 639-664.
Garn, S. M. 1970 The Earlier Gain and Later Loss of Cortical Bone in Nutritional Perspective. C. C Thomas, Springfield, Illinois.

1972 The course of bone gain and the phases of bone loss. Orthopedic Clinics of North America, 3: 503-520.

Garn, S. M., J. M. Nagy and S. T. Sandusky 1972 Differential sexual dimorphism in bone diameters of subjects of European and African ancestry. Am. J. Phys. Anthrop., 37: $127-129$.

Garn, S. M., A. K. Poznanski and K. Larson 1976 Metacarpal lengths, cortical diameters and areas from the 10 . State Nutrition Survey, including: estimated skeletal weights, weight, and stature for Whites, Blacks, and Mexican-Americans. In: Proceedings of the First Workshop on Bone Morphometry. Z. F. G. Jaworski, ed. University of Ottawa Press, pp. 367-391.

Giles, E. 1964 Sex determination by discriminant function analysis of the mandible. Am. J. Phys. Anthrop., 22: 129-136.

Giles, E., and O. Elliot 1963 Sex determination by discriminant function analysis of crania. Am. J. Phys. Anthrop., 21: $53-68$.

Krogman, W. M. 1962 The Human Skeleton in Forensic Medicine. C. C Thomas, Springfield, Illinois.

Phenice, T. W. 1969 A newly developed visual method of sexing the os pubis. Am. J. Phys. Anthrop., 30: 297-301.

Smith, R. W., Jr., and R. R. Walker 1964 Femoral expansion in aging women: implications for osteoporosis and fractures. Science, 145: 156-157.

Stewart, T. D. 1948 Medico-legal aspects of the skeleton. I. Age, sex, race, and stature. Am. J. Phys. Anthrop., n. s., 6: $315-321$.

1952 Hrdlicka's Practical Anthropometry. Fourth ed. The Wistar Institute of Anatomy and Biology, Philadelphia, Pennsylvania. 